\title{
The Real Effects of Relational Contracts
}

\section{Citation}

Blader, Steven, Claudine Gartenberg, Rebecca Henderson, and Andrea Prat. 2015. "The Real Effects of Relational Contracts." American Economic Review 105 (5): 452-56. https:// doi.org/10.1257/aer.p20151002.

\section{Permanent link}

http://nrs.harvard.edu/urn-3:HUL.InstRepos:37940889

\section{Terms of Use}

This article was downloaded from Harvard University's DASH repository, and is made available under the terms and conditions applicable to Open Access Policy Articles, as set forth at http:// nrs.harvard.edu/urn-3:HUL.InstRepos:dash.current.terms-of-use\#OAP

\section{Share Your Story}

The Harvard community has made this article openly available.

Please share how this access benefits you. Submit a story.

\section{Accessibility}




\section{The Real Effects of Relational Contracts}

\section{Steven Blader}

Department of Management and Organizations

New York University Stern School of Business

40 West $4^{\text {th }}$ Street

New York, NY 10012

sblader@stern.nyu.edu

212-998-0431

\section{Claudine Gartenberg (Corresponding Author)}

Department of Management and Organizations

New York University Stern School of Business

40 West $4^{\text {th }}$ Street

New York, NY 10012

cgartenb@stern.nyu.edu

212-998-0414

\section{Rebecca Henderson}

Harvard Business School

Soldiers Field

Boston, MA 02163

rhenderson@hbs.edu

617-495-8014

\section{Andrea Prat}

Columbia Business School

3022 Broadway

New York, NY 10027

Andrea.prat@columbia.edu

212-854-6176

Session Title: Organization, Management and Economic Growth Session Chair: Rebecca Henderson (organizer: John van Reenen) Discussants: None 


\section{The Real Effects of Relational Contracts}

\section{Steven Blader, Claudine Gartenberg, Rebecca Henderson and Andrea Prat ${ }^{\mathrm{i}}$}

How important are factors such as "firm culture" and "employee engagement" in driving firm performance? Increasing evidence from a wide range of fields suggests that productivity differs widely across firms, even after the inclusion of careful controls for factors such as capital intensity, labor quality and the structure of demand (See, for example, Chew et al., (1990) and Syverson (2004). Several researchers have suggested that one possible cause of this productivity dispersion is the heterogeneous adoption of managerial practices such as the use of high-powered incentive systems, explicit performance targets, selective recruiting and skills training (e.g., Kochan et al. 1986, Macduffie 1995, Ichniowski et al. 1997; Bloom et al. 2007, 2012 and 2013).

But a long tradition of work in organizational behavior and organizational psychology suggests that the successful adoption of productivity enhancing managerial practices requires complementary changes in the firm's "culture" or in the structure of social relationships within the firm (see for example Collins and Smith, 2006, Edmonson and Lei, 2014 and Hoffer Gittell, 2002). Recently Gibbons and Henderson (2013) have suggested that one way to formalize this insight is through a focus on the role of relational contracts within the firm. They suggest that competitively significant managerial practices rely for their effectiveness on the performance of actions that cannot be specified in advance or contractually verified ex post, citing, for example, Nordstrom's instruction to its sales associates to "use good judgment in all situations." They hypothesize that this implies that the performance effects of management practices will be contingent on the presence of appropriate relational contracts within the firm. 
While this is an intriguing idea and consistent with a number of qualitative accounts of the role of relational contracts in shaping firm performance (see, for example, Henderson and Helper, 2014 and Hoffer Gittell, 2002), so far as we are aware it has not been the subject of any systematic empirical test. In this paper we outline a research program designed to be a first step in this direction. We use the quasi-randomized roll out across multiple sites within a single firm of an intervention designed solely to change the nature of the social relationships within the site - an intervention we interpret as changing the relational contracts in place -- to explore two critical questions. First, we ask whether changing relational contracts alone has an effect on performance and second, we ask whether the new relational contracts are in any sense complements to managerial practices. We find support for both ideas.

\section{Research Site \& Design}

Our research site is a large US trucking company that operates in the less-than-truckload segment of the industry, transporting shipments that are smaller than a full truckload and larger than individual parcels. The company employs more than 10,000 drivers, nearly all of whom are nonunion hourly employees, across about 300 sites in the US and Canada. A central feature of these sites - and one that is crucial to our research design - is that they operate essentially independently. This feature allows us to employ research designs that randomize various treatments across sites to unpack the effects of relational contracts.

The company is arguably in the middle of transitioning from one relational contract to another via a decade-long program to roll out Lean Management (“lean”). Lean is a widespread management philosophy, inspired by the Toyota Production System, that encompasses both extensive cultural interventions and a broad array of formal practices. Our company divided their lean rollout into five phases and, at the time of our research, was midway through the first phase. 
Critically, this first phase involves no implementation of formal lean practices or changes to employee incentives. Instead, it consists primarily of introducing employees to Lean principles, including how "continuous improvement" (the organizing idea behind Lean Management) occurs primarily through teamwork, collective responsibility and the empowerment of front-line workers. In a relational contract context, this first phase can be interpreted as a costly effort by management to announce a change in the prevailing contract. This effort by the company is consistent with Gibbons and Henderson (2013) and Helper and Henderson (2014), both of which draw on prior research to suggest that the successful implementation of lean techniques requires the development of a complementary set of relational contracts.

For the purpose of our research, therefore, we interpret this first phase as a relational contract intervention. We refer to it as "the lean intervention" or "lean," even though Lean Management, in its fullest sense, is far broader and encompasses an extensive set of formal practices to manage the production process (which had not yet been initiated at our company).

For our research program, we make use of the lean intervention to study two questions: 1) do relational contracts have a direct effect on performance? 2) do relational contracts have an indirect effect through complementarities with management practices?

\section{A. Do relational contracts affect performance?}

To identify the causal impact of a relational contract on performance, we require a research design that randomly assigns a relational contract intervention to some sites and no intervention to others. A study of this nature is currently underway in which we have randomized the introduction of lean to sites that were untouched by the lean initiative at the start of our study. 
Since the results of that study are pending, here we report preliminary findings based on a cross-sectional comparison of sites that had and had not already received the lean intervention when our study commenced. From discussions with management, we believe that this previous assignment of lean can be plausibly considered quasi-random in that -- after an initial pilot program in 2011 - the lean rollout schedule was chosen solely to reduce the travel burden on the regional lean manager, and not by the anticipated success of lean at any particular site.

We record lean as a binary variable, capturing whether or not the first phase of lean had been initiated at the site at least three months before our data collection. For performance measures, we consider three measures of driver efficiency that directly reflect fuel usage and truck wear-and-tear: i) Gap Score, the percentage difference between the average actual and "potential" miles per gallon expended on a given route; ${ }^{1}$ ii) Excess Idle Time, a measure of the minutes that an engine idles beyond a designated time period, thereby wasting fuel, and iii) Total Fuel Lost, an aggregate measure of all the fuel wasted from idling, inefficient shifting, speeding and gearing. A higher value for any of these measures represents worse performance.

For this analysis, we use data from daily driver routes obtained between September 2013 and April 2014 across 73 lean and non-lean sites and 3,179 individual drivers. These sites comprise the control group of a separate study -- discussed below -- in which we randomized the public posting of driver performance results across lean and non-lean sites. Because those performance postings affected driving behavior, we exclude the treated sites from this analysis.

The histograms shown in Figure 1 show the average performance in lean and non-lean sites. We can see from these raw comparisons that driver performance in lean sites is consistently more efficient than in non-lean sites.

\footnotetext{
${ }^{1}$ The potential miles per gallon is calculated by the truck's on-board computer on the basis of optimal shifting and speed patterns, given weather conditions and route characteristics.
} 
Figure 1: Driver Performance at Lean and Non-lean Sites
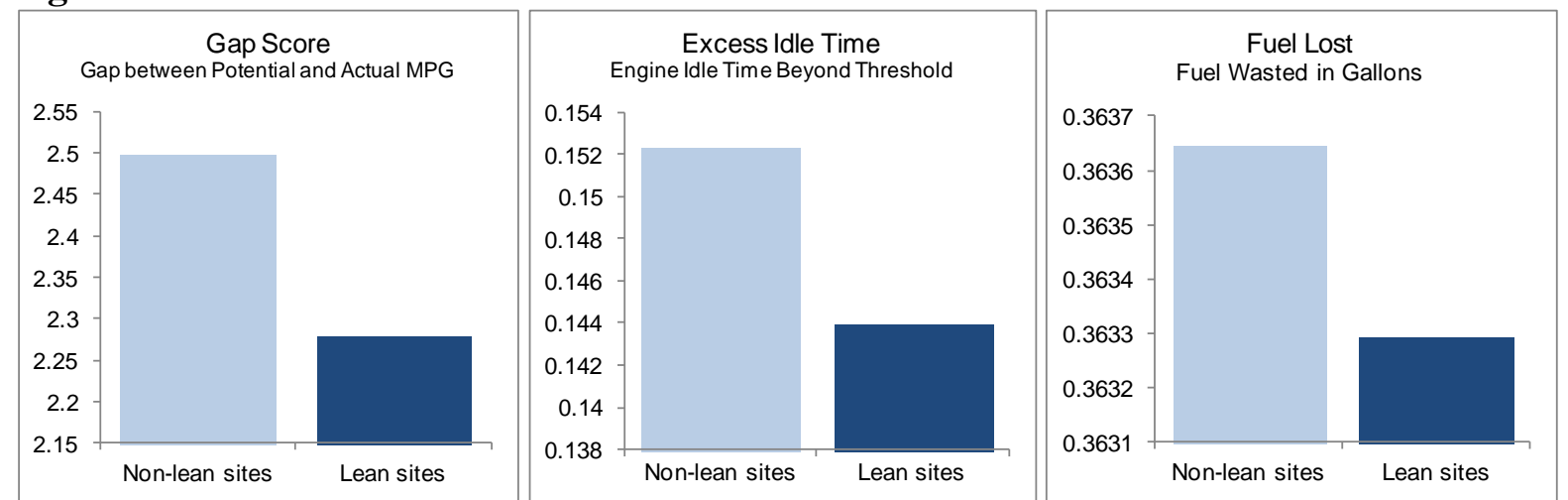

Table 1 shows similar results in a multivariate form. Lean sites are associated with a 7.4\% lower gap score, a $1.7 \%$ lower engine idling time and a $0.9 \%$ reduction in total fuel lost.

Table 1: Driver Performance by Lean and Non-lean sites

\begin{tabular}{llll}
\hline \hline Dependent variable: & Gap Score & $\begin{array}{l}\text { Excess Idle Time } \\
(2)\end{array}$ & $\begin{array}{l}\text { Fuel Lost } \\
(3)\end{array}$ \\
\hline Lean & $(1)$ & $-0.0165^{* * *}$ & -0.0089 \\
& $-0.0741^{* *}$ & $(0.0058)$ & $(0.0154)$ \\
Constant & $(0.0289)$ & 0.0482 & $0.1713^{* * *}$ \\
& $2.4735^{* * *}$ & $(0.0362)$ & $(0.0625)$ \\
\hline Controls & $(0.1633)$ & $\mathrm{Y}$ & $\mathrm{Y}$ \\
Observations & $\mathrm{Y}$ & 215,854 & 215,854 \\
Adjusted R-squared & 215,854 & 0.043 & 0.129 \\
\hline \hline
\end{tabular}

Notes: OLS estimates. Observations represent city driver-days. Controls include number of trucks at site, route distance, route potential MPG, and fixed effects for day of week, calendar date, date since EOBR rollout, lean manager, region code. Errors clustered by site, ***, **, * represent significance at $1 \%, 5 \%$ and $10 \%$.

Why might the lean intervention have this effect? On its face, this result is puzzling since no formal changes to operating practices or incentives were implemented. Our studies suggest that, under the lean relational contract, drivers adjust their beliefs that the company values and respects, rather than exploits, them. The observed effect is consistent with Halac and Prat's (2014) prediction that workers' belief in the firm's management system is a determinant of both effort and performance.

For evidence of this explanation, we worked with the company to administer an employee engagement survey on a subset of sites. The survey was individually identified in 
order to match responses to driver performance. The survey itself includes 37 questions on employee attitudes scored from 1-5, where 5 is the most positive response. For simplicity, we construct an engagement index that is the average of all 37 questions. Figure 2 shows the distributions of driver engagement for lean and non-lean sites. The distribution of driver engagement is noticeably shifted right for drivers in lean sites and has a smaller left-handed tail.

Figure 2: Distribution of Driver Engagement in Lean and Non-lean sites

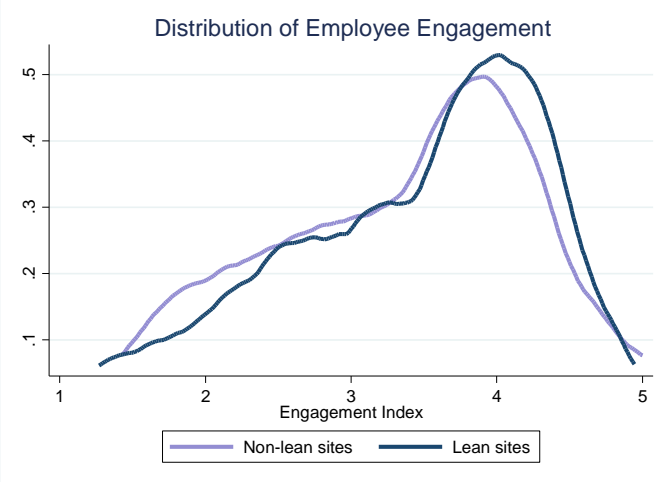

Figure 3 shows driver performance by engagement decile, relative to the lowest decile. While purely a correlational result, this figures shows a clear association between driver engagement and performance.

Figure 3: Driver Performance by Engagement Decile
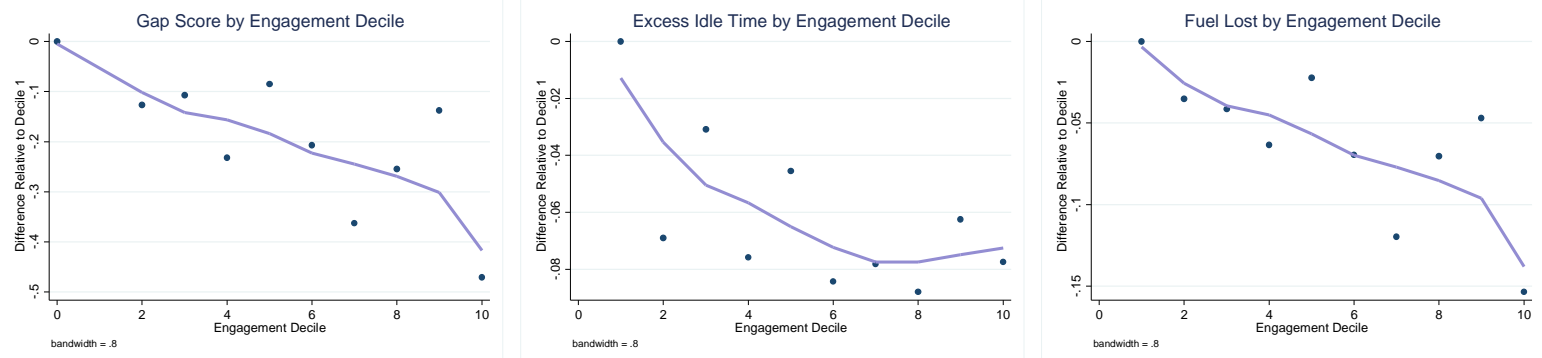

Table 2 shows the association between lean, driver engagement and performance. Without accounting for engagement, lean sites are associated with better performance. When engagement is included in the model, however, this association attenuates to insignificance.

Table 2: Lean, Driver Engagement and Performance

\begin{tabular}{|c|c|c|c|}
\hline \multirow[t]{2}{*}{ Dependent variable } & Gap Score & Excess Idle Time & Fuel Lost \\
\hline & (2) & (4) & (5) \\
\hline
\end{tabular}




\begin{tabular}{lllllll} 
Lean & $-0.2016^{*}$ & -0.1342 & $-0.0498^{* *}$ & -0.0315 & $-0.0890^{* * *}$ & $-0.0683^{* *}$ \\
& $(0.1148)$ & $(0.1195)$ & $(0.0208)$ & $(0.0232)$ & $(0.0301)$ & $(0.0320)$ \\
Engagement Index (Z) & & $-0.0669 *$ & & $-0.0182^{* *}$ & & $-0.0206^{*}$ \\
& & $(0.0368)$ & & $(0.0073)$ & & $(0.0114)$ \\
Constant & $3.4083^{* * *}$ & $3.4361^{* * *}$ & 0.0378 & 0.0454 & $0.3808^{* *}$ & $0.3893^{* *}$ \\
& $(0.4959)$ & $(0.5415)$ & $(0.0695)$ & $(0.0724)$ & $(0.1476)$ & $(0.1612)$ \\
\hline Controls & $\mathrm{Y}$ & $\mathrm{Y}$ & $\mathrm{Y}$ & $\mathrm{Y}$ & $\mathrm{Y}$ & $\mathrm{Y}$ \\
Observations & 21,669 & 21,669 & 21,669 & 21,669 & 21,669 & 21,669 \\
Adjusted R-squared & 0.112 & 0.121 & 0.067 & 0.073 & 0.171 & 0.177 \\
\hline \hline
\end{tabular}

Notes: OLS estimates. Observations represent city driver-days for the subset of observations with associated survey results. Engagement index is the z-scored average of the 37 survey questions. Controls include demographic measures (race, age, tenure), number of trucks at site, route distance, route potential MPG, and fixed effects for day of week, calendar date, date since EOBR rollout and region. Errors clustered by site, ***, **, * represent significance at $1 \%, 5 \%, 10 \%$.

Together, these results show that the lean intervention is associated with higher employee engagement, which is in turn correlated with better driving performance. Applying a causal interpretation, based on the quasi-random lean assignment, the findings become intriguing for two reasons: first, they imply that relational contracts, independent of formal practices, can influence performance. Second, they suggest that relational contracts can, in fact, be changed by managers, albeit in a costly, time-consuming way.

\section{B. Do relational contracts affect the outcomes of management practices?}

Our second research question asks whether complementarities exist between relational contracts and management practices. This section draws on a more extensive study by Blader, Gartenberg and Prat (2015) (BGP).

Driver performance data, including the data analyzed in the previous section, is produced by an electronic on-board recorder (EOBR) system that was rolled out by the company in the second half of 2013. A natural question for management as part of that rollout is whether drivers should only be made aware of their individual performance or whether they should also learn about their colleagues' performance.

We worked with management to implement a three by two research design, in which we randomly assigned three conditions across lean and non-lean sites: a control condition with no 
public performance posting and two treatment conditions. For the first treatment, beginning six weeks after the EOBR rollout, managers posted sheets with driver names next to driver performance on a weekly basis in the site meeting area. For the second treatment, managers replaced names with anonymized driver identifiers, such that drivers knew their own performance and the site distribution, but did not know each other's individual performance.

BGP finds drivers respond to the performance postings in opposite ways, depending on whether they are assigned to lean and non-lean sites. In non-lean sites, drivers respond positively, improving their performance by $1-5 \%$ relative to the control group. In contrast, in lean sites, drivers respond negatively, with performance deteriorating by 3-11 percent.

Figure 4 reproduces the second figure in BGP that depicts the differential driver response. Interestingly, only drivers in sites with the named performance postings (our first treatment) exhibited a response to the performance postings. Anonymized postings had no effect.

Figure 4: Driver Response to Performance Postings in Lean and Non-lean Sites
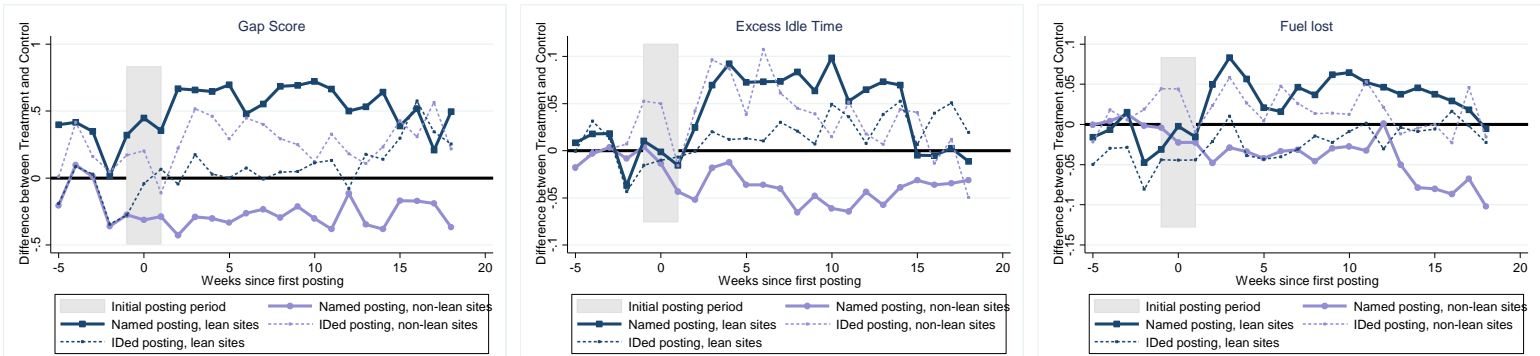

Note: Figure reproduced from Blader, Gartenberg and Prat (2015)

Altogether, the results of our two analyses suggest that relational contracts do in fact affect performance both directly and via complementarities with management practices.

\section{Directions for further work}

These results are intriguing, but they leave many questions unanswered. For example, how do relational contracts interact with other aspects of job design, such formal incentives, the degree of workplace decentralization and the nature of actual work performed? How do they 
interact with market conditions, such as the intensity of competition, uncertainty and technological advancement? Finally, more work is required to understand the contracts themselves. What is the actual underlying mechanism by which they influence productivity? And finally, how can they be credibly altered and sustained? Some of these questions we hope to explore at this site and in other settings. We also hope this work attracts broader interest and other empirical research on the topic.

\section{References}

Blader, Steven, Gartenberg, Claudine \& Andrea Prat “The Contingent Effect of Management Practices”. Working paper, New York University, October 2014.

Bloom, Nicholas, and John Van Reenen. 2007. “Measuring and Explaining Management Practices across Firms and Countries.” Quarterly Journal of Economics 122: 1351-1408.

Bloom, Nicholas, Raffaella Sadun, and John Van Reenen. 2012. “Americans Do I.T. Better. US Multinationals and the Productivity Miracle.” American Economic Review 102: 167-201.

Chew, Bruce, Kim Clark, and Timothy Bresnahan. 1990. "Measurement, Coordination and Learning in a Multiplant Network,” in Robert Kaplan (ed.) Measures for Manufacturing Excellence. Boston: Harvard Business School Press, pp. 129-162.

Collins CJ, Smith KG. 2006. Knowledge exchange and combination: the role of human resource practices in the performance of high-technology firms. Acad. Manag. J. 49(3):544-60

Edmondson, Amy C., and Zhike Lei. "Psychological Safety: The History, Renaissance, and Future of an Interpersonal Construct." Annual Review of Organizational Psychology and Organizational Behavior 1 (2014).

Gibbons, Robert and Rebecca Henderson "What do managers do? Exploring Persistent Performance Differences among Seemingly Similar Enterprises" Chapter 17, pages 680- 
731 in The Handbook of Organizational Economics, Robert Gibbons and John Roberts, Editors, Princeton University Press, Princeton and Oxford, 2013.

Halac, Marina and Andrea Prat. Managerial Attention and Worker Engagement. CEPR Discussion Paper 10035, August 2014.

Helper, Susan and Rebecca Henderson, 2014 “Management Practices, Relational Contracts and the Decline of General Motors”. Journal of Economic Perspectives, Volume 28, Number 1—Winter 2014-Pages 49-72

Hoffer Gittell, Jody, “Coordinating Mechanisms in Care Provider Groups: Relational Coordination as a Mediator and Input Uncertainty as a Moderator of Performance Effects” Management Science Vol. 48, No. 11, November 2002 pp. 1408-1426

Ichniowski, Casey, Kathryn Shaw, and Giovanni Prennushi. 1997. “The Effects of Human Resource Management Practices on Productivity: A Study of Steel Finishing Lines.” American Economic Review 87: 291-313.

Lee, SKJ \& K. Yu “Corporate Culture and Organizational Performance” Journal of Management Psychology, 2004.

MacDuffie, John Paul. 1995. “Human Resource Bundles and Manufacturing Performance: Organizational Logic and Flexible Production Systems in the World Auto Industry.” Industrial and Labor Relations Review 48: 197-221.

Syverson, Chad. 2004a. "Product Substitutability and Productivity Dispersion.” Review of Economics and Statistics 86: 534-550.

\footnotetext{
${ }^{\text {i }}$ Steven Blader, NYU Stern School of Business, 40 West $4^{\text {th }}$ Street, NY 10012, sblader@stern.nyu.edu; 212-9980431. Claudine Gartenberg, NYU Stern School of Business, 40 West $4^{\text {th }}$ Street, NY 10012, cgartenb@stern.nyu.edu; 212-998-0414. Rebecca Henderson, Harvard Business School, MA 02163, rhenderson@hbs.edu; 617-495-8014. Andrea Prat, Columbia Business School, 3022 Broadway, NY 10027, andrea.prat@columbia.edu; 212-854-6176
} 